Antonio Scocozza. Catedrático de Lengua, Cultura e Instituciones de los Países de Lengua Española por el Dipartimento di Scienze Politiche, Sociali e della Comunicazione de la Università degli Studi di Salerno. Es autor de numerosas publicaciones sobre la lengua, la historia, la cultura y la filosofía de los países del área hispanoamericana, habiéndose dedicado al análisis de las contribuciones de autores como Andrés Bello, Simón Bolívar, José Rafael Pocaterra, Rómulo Gallegos, etc. Es director de varias revistas especializadas y colecciones de su sector (Extremo Occidente, De Sur a Sur, Cultura Latinoamericana, Rocinante). Desde el año 2013 es el delegado del rector de la Università di Salerno para América Latina. Fundador del Istituto di Studi Latinoamericani I.S.LA y director de la Maestría Internacional en Ciencia Política para la paz y la integración de los pueblos, por la Universidad Católica de Colombia.

Contacto: ascocozza@unisa.it

Mariarosaria Colucciello. Doctora en "Teoria e Storia delle Istituzioni Politiche" por la Università degli Studi di Salerno. Actualmente tiene una beca de investigación y es profesora contratada de Lingua, Cultura e istituzioni dei Paesi di Lingua Spagnola por el Dipartimento di Scienze Politiche, Sociali e della Comunicazione de la Università di Salerno. Su primera línea de investigación fueron los aspectos histórico-políticos de la teología de la liberación latinoamericana, cuyo análisis llevó a la publicación de muchos artículos y de la monografía Libertà come speranza. Utopia e prassi politica in America Latina: Gustavo Gutiérrez, Le Càriti Editore, Firenze, 2011. Su actual campo de trabajo es la paremiología en sus aspectos contrastivos ítalo-hispanos y en sus derivaciones latinas, y que ha llevado a la participación en muchas conferencias nacionales e internacionales, a la publicación de varios artículos y de la monografía Asno, mujer y nuez... Origen y uso de la paremia en la lengua española, Planeta, Bogotá, 2014.

Contacto: mcolucciello@unisa.it 


\section{TEOLOGÍA DE LA LIBERACIÓN Y OPCIÓN POR LOS POBRES. GUSTAVO GUTIÉRREZ Y LAS CRÍTICAS A LAS FORMAS ESTABILIZADAS DEL PODER RELIGIOSO}

Mariarosaria Colucciello - Antonio Scocozza ${ }^{1}$

Università degli Studi di Salerno

\section{THEOLOGY OF LIBERATION AND CHOICE FOR THE POOR. GUSTAVO GUTIÉRREZ AND THE CRITIQUE OF ESTABLISHED FORMS OF RELIGIOUS POWER}

DOI: $10.17450 / 150206$

Fecha de recepción 20 de agosto 2015; fecha de aceptación 25 de setiembre 2015. Este artículo se ha desarrollado en el ámbito de un proyecto de investigación del Diparti-

1. Están a cargo de Antonio Scocozza los párrafos 2 y 3, y a cargo de Mariarosaria Colucciello los párrafos 4 y 5 . La introducción (1) y las conclusiones (6) son comunes. 
mento di Scienze Politiche, Sociali e della Comunicazione de la Università di Salerno, del cual forman parte los dos autores.

\section{Resumen}

En este artículo nos proponemos analizar las etapas que, desde principios de los años setenta hasta hoy, llevaron al 'padre de la teología de la liberación', Gustavo Gutiérrez Merino, a 'innovar la teología' latinoamericana y mundial en general. La opción para los pobres se ha convertido en el eje de su mensaje que, empezando por el libro Teología de la liberación. Perspectivas, sigue caracterizando a su pensamiento, pues critica abiertamente las formas estabilizadas del poder religioso.

\section{Palabras clave}

Teología de la liberación, Gustavo Gutiérrez, innovación, opción para los pobres.

\section{Abstract}

The purpose of this article is to illustrate the stages that Gustavo Gutiérrez Merino, the 'father of liberation theology', traced to innovate Latin-American and world theology from the early seventies to the present. The option for poor people became the load-bearing axis of his message that, from the book Teología de la liberación. Perspectivas, continues to be the setting of his thought, which is an open criticism to stabilized forms of religious power.

\section{Keywords}

Liberation Theology, Gustavo Gutiérrez, innovation, option for the poor.

\section{Introducción}

El propósito de este artículo es analizar muy brevemente las etapas que, desde principios de los años setenta, llevaron a Gustavo Gutiérrez Merino, el llamado 'padre de la teología de la liberación', a erradicar la vieja y obsoleta teología europea del subcontinente, creando una interfaz específicamente latinoamericana.

Este proceso llevó a una innovación generalizada de la teología latinoamericana, que sentó sus bases en la primera obra programática acerca del asunto, Teología de la libera- 
ción. Perspectivas, que Gustavo Gutiérrez publicó por primera vez en 1972 y que sigue siendo el evangelio para todos los que -antaño como ahora- se acogen a la ley de Dios y de los hombres para mejorar su situación de incertidumbre político-social.

Primero, insertaremos rápidamente la figura de Gutiérrez en el período histórico en que desarrolló su acción de profesor y teólogo; luego esbozaremos su idea acerca del replanteamiento desde las raíces de la misma noción de teología, llegando a la 'construcción' del concepto de teología de la liberación. ${ }^{2}$

El intento más acabado de sistematización de esas ideas fue la obra de 1972: en ella se ofrecen intuiciones profundas como pistas de solución a los problemas planteados, dando, además, interesantes indicaciones bibliográficas y referencias a testimonios y documentos.

La novedosa opción para los pobres es el eje de su discurso, el objetivo último, el logro necesario y, al mismo tiempo, de difícil realización que impregna su mensaje de amor para los últimos, los pobres y los débiles, pues para los protagonistas silentes de una lucha -tal vez desigual aunque no imposible- contra las formas estabilizadas del poder religioso.

\section{Los albores del análisis teológico-social de Gustavo Gutiérrez}

A principios de los años sesenta, mientras Gustavo Gutiérrez Merino consagraba su vida a Dios, empezaba una década llena de esperanzas para América Latina: en la mayoría de las naciones latinoamericanas volvía a flamear la bandera de la democracia tras períodos más o menos largos de dictaduras militares corruptas.

En los mismos años en que la revolución empezada en Cuba por Fidel Castro echaba a Fulgencio Batista, en todo el subcontinente la lucha armada parecía haberse convertido

\footnotetext{
2. Sobre este argumento, véanse entre otros: H. Assmann, Teología desde la praxis de liberación, Ediciones Sígueme, Salamanca, 1973; A. Bandera, La Iglesia ante el proceso de liberación, Biblioteca de Autores Cristianos, Madrid, 1975; L. Boff y C. Boff (eds.), Cómo hacer teología de la liberación, Ediciones Paulinas, Madrid, 1985; L. Boff y M. Hathaway, El Tao de la liberación. Una ecología de la transformación, Trotta Madrid, 2014; R. Gibellini, Il dibattito sulla Teologia della Liberazione, Queriniana, Brescia, 1990; K. Lehman, "Problemas metodológicos y hermenéuticos de la 'teología de la liberación”, en Comisión Teológica Internacional, Teología de la liberación, Biblioteca de Autores Cristianos, Madrid, 1978, pp. 3-42; J. C. Scannone, Teología de la Liberación y praxis popular. Aportes críticos para una teología de la liberación, Ediciones Sígueme, Salamanca, 1976; S. Scatena, La teologia della liberazione in America Latina, Carocci, Roma, 2008; D. M. Bell Jr., Teología de la liberación tras el fin de la historia, Nuevo Inicio, Granada, 2009; A. Paoli, Dialogo della liberazione, Aragno, Torino, 2009; J. M. Vigil, L. E. Tomita y M. Barros, Por los muchos caminos de Dios. Teología latinoamericana pluralista de la liberación, Abya-Yala, Quito, 2006; R. Giuè, Chiesa e liberazione. Linee essenziali di teologia della liberazione, Tau Editrice, Todi, 2013; M. Colucciello, Libertà come speranza. Utopia e prassi politica in America Latina: Gustavo Gutiérrez, Le Cáriti Editore, Firenze, 2011; etc.
} 
en la reacción a las desigualdades y a las injusticias sociales que aumentaban cada vez más el desfase entre ricos y pobres.

Con sus estudiantes de la Universidad Católica de Lima -en la que enseñaba teología y ciencias sociales-, Gustavo Gutiérrez vivió esta experiencia y también la novedad del Concilio Vaticano II, que -convocado por Juan XXIII para octubre de 1962- desconcertó a todos los que creían que la Iglesia-institución estuviera desinteresándose de los problemas socio-religiosos del continente suramericano.

Los resultados a los que llegó el Concilio lo satisfacieron por la gran importancia que la teología que él había estudiado de joven adquiría en el panorama mundial; sin embargo, un sentimiento de amargura hacia lo que podría ser y que no fue empezó a angustiarlo e indignarlo al mismo tiempo: la pobreza y la injusticia social seguían siendo condiciones endémicas de América del Sur y el Concilio parecía haberlo desatendido. ${ }^{3}$

Justo antes de que el Concilio acabara, en la ciudad brasileña de Petrópolis por primera vez todos los teólogos latinoamericanos se encontraban para enfocar los intereses realmente suramericanos y, en aquella ocasión, Gustavo Gutiérrez destacó por poner un interrogante nuevo, relativo a la posibilidad de separar 'el hombre latinoamericano' del resto del género humano, considerándolo casi una entidad específica y única: claro estaba, su análisis teológico-social acababa de empezar, era inmaduro por no haber terminado el Concilio ni comenzado el encuentro de Medellín; sin embargo, se esbozaban los enfoques de sus teorías posteriores.

La noción de "hombre latinoamericano" daba pábulo a diferentes interpretaciones, pues tres eran los sujetos sociales del subcontinente: la masa popular, que representaba la mayoría de la población; la élite intelectual, cuya finalidad era encabezar el proceso de transformación en marcha en América Latina; y la oligarquía conservadora, que rehuía de cualquier tipo de reforma social. ${ }^{4}$

Frente a esta variedad de condiciones y modelos de vida, para Gutiérrez la Iglesia debía acompañar a las masas durante ese difícil proceso de personalización de la fe y de reivindicación social, aun reconociendo la difícil operacionalidad en un período histórico caracterizado por profundos y generalizados cambios.

No obstante, tras acabar el Concilio, muchos notaron que la Iglesia latinoamericana parecía abrirse a la modernidad con apabullante vitalidad; ${ }^{5}$ el mismo Pablo VI incenti-

\footnotetext{
3. Gustavo Gutiérrez explica muy claramente sus sentimientos en L. Ceci, La Teologia della Liberazione in America Latina. L'opera di Gustavo Gutiérrez, Franco Angeli, Milano, 1999, p. 57.

4. Ibid., p. 62.

5. En una entrevista, François Houtart destacó el gran dinamismo de la Iglesia y de la Conferencia Episcopal Latinoamericana (Celam), un organismo extremadamente progresista, formado por obispos que habían tenido relaciones con
} 
vaba este dinamismo, incitando al obispado a interesarse por lo social porque la pastoral debía involucrarse en este, no solo enseñarlo de forma abstracta, sino traducirlo en acciones concretas. ${ }^{6}$

Las palabras del Pontífice parecían insertarse perfectamente en el nuevo clima social de la Conferencia de Teología Pastoral de Santiago de Chile de 1966, en la que participó el mismo Gutiérrez: en su ponencia titulada Libertad religiosa y diálogo salvador, ${ }^{7}$ él cotejaba la Iglesia y la sociedad y se interrogaba sobre todo acerca de las modalidades de la acción religiosa, esto es, sobre cómo la primera podría actuar en el subcontinente, puesto que su problema más apabullante no era el ateísmo o la laicización, sino la pobreza y el subdesarrollo; unos temas que acompañarían siempre al joven estudioso que, a partir de 1968, llegaría a ser cada vez más famoso, con sus pensamientos y obras que revolucionarían la manera de hacer teología.

\section{Hacia la formación de una teología novedosa}

El período entre 1968 y 1971 fue muy importante para la conciencia histórica del continente: de hecho, a pesar de que los grupos oligárquicos latinoamericanos, apoyados por las potencias hegemónicas extranjeras, reforzaron sus posiciones de dominación, hubo una serie de acontecimientos históricos -como la consolidación de la revolución cubana, el principio de la peruana y la iniciada vía chilena al socialismo- que despertaron las esperanzas de los grupos de avanzada y de los sectores populares tradicionalmente explotados.

Con palabras de Manzanera, surgió una conciencia social crítica que, a partir de una minoría concientizada, comienza a expandirse a los sectores populares, que adquieren una comprensión de la situación de dependencia en la que están mantenidos-económica, política y culturalmente- y reflexionan activamente sobre ella en orden a descubrir las causas más profundas y los medios para superarlas, tanto a nivel local como nacional e incluso continental. ${ }^{8}$

el extranjero y que supieron apreciar las novedades y las transformaciones en ámbito religioso. Cfr. P. Eleta, Un percorso intellettuale dai primi passi della sociologia della religione latino-americana: intervista a François Houtart, en Roberto Cipriani, Paula Eleta (eds.), Identità e mutamento nel religioso latinoamericano. Teorie e ricerche, Arnaldo Testi, Franco Angeli, Milano, 1997, pp. 141-160, pp. 143-144.

6. Pablo VI, Enseñanzas al pueblo de Dios, Editorial BAC, Madrid, 1972.

7. Cfr. G. Gutiérrez, Libertad religiosa y diálogo salvador, en Id., Salvación y construcción del mundo, Nova Terra, Santiago del Chile-Barcelona, 1968.

8. M. Manzanera, Teología, salvación y liberación en la obra de Gustavo Gutiérrez. Exposición analítica, situación teórico-práctica y valoración crítica, Universidad del Deusto, Bilbao, 1978, pp. 37-38. 
También la Iglesia latinoamericana intentó buscar su posición en este cambio generalizado de circunstancias, del que Gutiérrez había subrayado la importancia, incitando la institución católica a conformar el itinerario eclesiástico a la realidad.

Mientras tanto, minorías crecientes de sacerdotes y simples cristianos iban enterándose de la situación de injusticia y opresión de mucha parte de la población latinoamericana y empezaron a asumir posiciones radicales hasta planteando la necesidad de una transformación social revolucionaria.

Al no aguantar más las decenas de teorías pseudocientíficas sobre el tema, estos nuevos sujetos religioso-políticos -que al principio solo eran una pequeña parte del clero latinoamericano- se hicieron cautivar por los propósitos de su compañero peruano, cuyos planteamientos se hacían cada vez más más tajantes.

De hecho, las nuevas condiciones del subcontinente lo indujeron a considerar que ya no era suficiente adaptarse teológicamente al cambio, sino que era menester "replantear desde sus raíces la misma noción de teología en orden a elaborar una reflexión teológica que responda plenamente a una inteligencia de la fe en la situación de la Iglesia en América Latina".

De ahora en adelante, seguirá proponiendo estos planteamientos por doquier, empezando por el Encuentro Nacional del movimiento sacerdotal de la Oficina Nacional de Investigación Social -ONIS- con la ponencia Hacia una teología de la liberación, ${ }^{10}$ cuyo título contenía la partida de nacimiento del movimiento.

Los dos sustantivos del título se convertían en el banco de pruebas de esta corriente para la cual la teología dejaba de ser la aglomeración de verdades abstractas para convertirse en "una reflexión, es decir, un acto segundo, es un volver atrás, re-flexionar, viene después de la acción. La teología no es lo primero, lo primero es el compromiso; la teología es una inteligencia del compromiso, el compromiso es acción; la teología viene después". 11

En cambio, a pesar de dar pábulo a interpretaciones heterogéneas, ${ }^{12}$ el término liberación había sido hábilmente insertado por Gutiérrez en el necesario y espontáneo proceso de rescate y emancipación humanos.

\footnotetext{
9. Ibid., p. 40 .

10. G. Gutiérrez, Hacia una Teología de la liberación, serie 1, doc. 16, MIEC-JECI, Montevideo, 1969.

11. Ibid., p. 2.

12. A este propósito, véase M. Colucciello, "Independencia como liberación”, en Cultura Latinoamericana. Revista de estudios interculturales, año 2011 (2), n. 14, pp. 43-54.
} 
Y mientras la nueva noción de 'liberación' adquiría un lugar hermenéutico importante, un constante y genial enlace entre estos dos conceptos convertía al hombre en agente de sí mismo, de su destino o de la historia en su totalidad, llevando a una transformación no opcional o accidental, sino indispensable y precisa, desembocando en la realización de un proceso libertador irreversible.

En 1968, la II Conferencia General del Episcopado Latinoamericano de Medellín contribuyó a aclarar los últimos hallazgos teológico-intelectuales, y los dieciséis documentos que brotaron de ella no los desmintieron, mientras la palabra 'cambio' adquiría matices nuevos: "la salvación del ser humano no sólo acontece dentro de las paredes de la Iglesia cuando se predica la palabra de Dios y se imparten los sacramentos, sino que la salvación también se da en la vida diaria de cada hombre y en el desarrollo de la historia de los pueblos [...] el signo de los tiempos predominante y que acapara la preocupación de todos es el mismo del Concilio: el cambio". ${ }^{13}$ Gutiérrez no participó de forma oficial en la comisión que redactó estos documentos, pero contribuyó con consejos y sugerencias al Documento sobre la pobreza que encabezaría la "Iglesia pobre entre los pobres", de la que él fue el representante más destacado.

En la Conferencia de Cartigny (Suiza) de 1969, organizada por la Société Oecuménique pour le Développement et la Paix-SODEPAX-Gutiérrez presentó una ponencia titulada Notes on Theology of Liberation, inmediatamente cambiada por los organizadores con The Meaning of Development, haciendo hincapié en el concepto de 'desarrollo', mucho más politically correct.

Desatendiendo este cambio, antes que todo Gutiérrez le reconocía otro significado al subdesarrollo endémico del subcontinente que, en su opinión, derivaba de la fe practicada por sus habitantes, quienes se estaban despertando del entorpecimiento que los había enredado hasta aquel momento, pero que empezaban a tomar el buen camino de la revolución social porque, solo por medio de esta, América Latina superaría la situación de dependencia y abriría el camino hacia una sociedad en la que el hombre fuera libre de toda servidumbre con los pobres y oprimidos en su lucha por la liberación. ${ }^{14}$

13. V. Menéndez Martínez, La misión de la Iglesia. Un estudio sobre el debate teológico y eclesial en América Latina (19551992), con atención al aporte de algunos teólogos de la Compañía de Jesús, Editrice Pontificia Università Gregoriana, Roma, 2002, pp. 42-43.

14. G. Gutiérrez, "Notes on Theology of Liberation", en In Search of Theology of Development. Papers from a Consultation on Theology and Development held by SODEPAX in Cartigny, Switzerland, November 1969, Imprimerie La Concorde, Lausanne, 1970, p. 136. 


\section{Teología de la Liberación. Perspectivas}

La ponencia suiza fundamentó sus elaboraciones siguientes, sobre todo las del libro Teología de la liberación. Perspectivas. ${ }^{15}$

Desde las primeras páginas, transparentaba la clara certidumbre de que no se trataba de un trabajo acabado, porque el autor era consciente de la dificultad de sintetizar en algunas centenares de páginas -aunque impregnadas de una excepcional madurez intelectual- la complejidad de una problemática que, precisamente por ser histórica, podía estar sometida a cambios o alteraciones in fieri.

A pesar de nacer en el subcontinente, la teología de la liberación que él había racionalizado no tenía la reivindicante presunción de ser específicamente latinoamericana, porque los problemas y las preguntas que se planteaba no se podían circunscribir a una parte del mundo.

Tal como cualquier otra teología, la de la liberación pretendía ser -refiriéndonos a Joâo Batista Libânio- universal o absoluta y, al mismo tiempo, específica y relativa: universal, porque atañía a la fe en su totalidad y de cualquier parte del mundo; específica, porque una situación determinada, ya sea geográfica o histórica, permite una percepción mejor de otro tanto determinado tema religioso. ${ }^{16}$

Sin embargo, la teología de Gutiérrez tampoco quería contraponerse a la europea, a pesar de no compartirla totalmente, porque opinaba que la diversidad de los lugares contribuía a enriquecer la argumentación teológica.

Simplemente, él quería innovar la teología, mirándola desde otra perspectiva, y para hacerlo era necesario que se siguieran no solo y exclusivamente las reglas clásicas de la moral cristiana - una premisa fundamental que la teología de la liberación no desatendió nunca en su continuo esfuerzo para fusionarse con la experiencia espiritual- sino que se partiera imprescindiblemente de una situación de sufrimiento. ${ }^{17}$

La teología era sabiduría y saber racional, "meditación sobre la Biblia, orientada al progreso espiritual $[y]$ modelo de todo cristiano deseoso de enderezar sus pasos por la

15. G. Gutiérrez, Teología de la liberación. Perspectivas, Ediciones Sígueme, Salamanca, 1975.

16. J. B. Libânio, Gustavo Gutiérrez, Edições Loyola, São Paulo, 2004, cap. I.

17. Gutiérrez subrayó este aspecto también en otra obra: G. Gutiérrez, Hablar de Dios desde el sufrimiento del inocente. Una reflexión sobre el libro de Job, Ediciones Sígueme, Salamanca, 2006. Aquí destacó los dos ejes más importantes del discurso teológico que, en su opinión, llevan a la liberación: el "lenguaje profético" y el de la "contemplación”. Con el primero, él implicaba una especie de apertura a las necesidades de los desamparados, esforzándose para intentar solucionar sus problemas; en cambio, con el segundo el autor pretendía alcanzar el misterio y el amor del Todopoderoso. 
senda estrecha de la santidad”, ${ }^{18}$ y ciencia -según el modelo propuesto por Tomás de Aquino- "disciplina intelectual, fruto del encuentro de la fe y la razón”. ${ }^{19}$

Por lo que atañe al saber racional, Gutiérrez explicó por qué fides quaerens intellectum, esto es, por qué era la fe la que exigía la inteligencia: en resumidas cuentas, creer necesitaba de racionalidad y de las ciencias sociales y humanas para discernir la realidad y sistematizar las intuiciones que, de lo contrario, serían difícilmente comprensibles.

Más allá de esta importante aclaración, la teología debía convertirse en una reflexión evaluativa, en "un pensamiento crítico de sí misma, de sus propios fundamentos", ${ }^{20}$ para afrontar un discurso maduro, consciente, "en plena posesión de sus instrumentos conceptuales" ${ }^{21}$ y totalmente integrado en la realidad que lo rodeaba.

De ahí la afirmación tan significativa de Gutiérrez acerca de la pirámide cronológica y la escala de valores del misterio teológico: "la teología es reflexión, actitud crítica. Lo primero es el compromiso de caridad, de servicio. La teología viene después, es acto segundo".22

La 'praxis histórica' no solo se convertía en el objeto principal de la función crítica de la teología, sino también en el punto de partida y el contexto de las dos aplicaciones teológicas; ${ }^{23}$ y ese de la praxis histórica fue el argumento más empleado por los teólogos de la liberación y por Gutiérrez, como cuando sostuvo que la teología, como reflexión crítica de la praxis histórica, es así una teología liberadora, una teología de la transformación liberadora de la historia de la humanidad y, per ende, también, de la porción de ella -reunida en "ecclesia" - que confiesa abiertamente a Cristo. Una teología que no se limita a pensar el mundo, sino que busca situarse como un momento del proceso a través del cual el mundo es transformado: abriéndose -en la protesta ante la dignidad humana pisoteada, en la lucha contra el despojo de la inmensa mayoría de los hombres, en el amor que libera, en la construcción de una nueva sociedad, justa y fraternal- del reino de Dios. ${ }^{24}$

\footnotetext{
18. G. Gutiérrez, Teología de la liberación. Perspectivas, cit., p. 23.

19. Ibid., p. 25.

20. Ibid., p. 34 .

21. Ibid.

22. Ibid.

23. Para Libânio, similar programa teológico-crítico realizaba antes que todo una teología de la praxis, sacando de la práctica histórica de los cristianos los elementos indispensables para su elaboración teológica. Se realizaba una teología para la praxis como finalidad última, en detrimento de la misma fe; una teología en la praxis, por estar insertada en el itinerario histórico-político de los pobres y, finalmente, una teología desde la praxis porque su validez y la moralidad de sus propósitos se sometían a los mismos destinatarios del mensaje y del proceso libertadores. Cfr. la introducción de J. B. Libânio, Gustavo Gutiérrez, cit.

24. G. Gutiérrez, Teología de la liberación. Perspectivas, cit., pp. 40-41.
} 
De ahí que la noción de liberación se insertara en la más amplia expresión "praxis histórica de liberación", caracterizada por tres niveles de significado-socio-político, histórico-utópico y redentivo-salvador- que aquí Gutiérrez analizó de forma más sistemática.

El nivel socio-político atañía a la categoría del 'desarrollismo' que triunfó en el subcontinente durante la década de los años cincuenta del siglo pasado porque se creía que este era un proceso social global que aumentaría la riqueza y el bienestar comunes; respecto de este término -para él infructuoso- Gutiérrez prefirió los de "dependencia" y "liberación".

Además de las clases sociales oprimidas, el nivel histórico-utópico atañía a toda la humanidad, al sujeto-hombre en general, quien quiere construir en la tierra una sociedad fraternal y de comunión entre todos los seres humanos.

Obviamente -y aquí viene el tercer nivel, el redentivo-salvador-, el hombre de hoy no aspira solo a liberarse de aquello que, viniendo del exterior, le impide realizarse en tanto que miembro de una clase social, de un país o de una sociedad determinada. Busca, igualmente, una liberación interior, en una dimensión individual e íntima. Una liberación en un plano no solo social, sino también psicológico. Pero libertad interior entendida no como una evasión ideológica del enfrentamiento social, como la interiorización de una situación de servidumbre, sino en referencia real al mundo del psiquismo humano. ${ }^{25}$

Así que la salvación y la liberación se entrelazaban de forma indisoluble, aunque no se confundían: en particular, la salvación ya no era algo circunscrito a las paredes de la Iglesia como antaño, sino revela una faceta que no aparecía en la perspectiva anterior. La salvación no es algo 'ultramundano', frente a lo cual la vida presente sería solo una prueba. La salvación -comunión de los hombres con Dios y comunión de los hombres entre ellos- es algo que se da, también, real y concretamente desde ahora, que asume toda la realidad humana, la transforma, y la lleva a su plenitud en Cristo. ${ }^{26}$

\section{La opción preferencial: los pobres}

Los pobres llevan siendo desde siempre los protagonistas de la reflexión teológica de la liberación; incluso podríamos decir que -junto con los temas relacionados al método 
específicamente teológico y a la evangelización- los pobres representan "el núcleo más antiguo y vigente de este esfuerzo de inteligencia de la fe" ${ }^{27}$.

El término 'pobreza' - para Gutiérrez muy ambiguo-implicaba diferentes significados.

La 'pobreza material' era la "carencia de bienes económicos necesarios para una vida humana digna de ese nombre" ${ }^{28}$ y los sujetos históricos caracterizados por esa condición destacaban por ser una colectividad de personas de fe obligadas a vivir, de forma infrahumana y escandalosa, una vida humillante de la que la conciencia moderna no podía sino rehuir, ya que atentaba contra la dignidad humana y la voluntad de Dios Padre.

Y si para muchos medios cristianos la pobreza material había adquirido una acepción positiva, "un ideal humano y religioso, un ideal de austeridad y de indiferencia frente a los bienes de este mundo, condición de una vida conforme al evangelio", ${ }^{29}$ una fatalidad que afectaba a algunos sujetos aislados quienes se convertían en el eje de la conmiseración del creyente, ahora los pobres empezaban a tomar conciencia de su situación de indigencia y a aborrecerla, por lo cual "estamos ante una pobreza colectiva que crea lazos de solidaridad entre los que la sufren y los lleva a organizarse para luchar contra esta situación y contra los que usufructúan de ella" ${ }^{30}$

Explicar la 'pobreza inmaterial o espiritual' era aún más difícil y podría conllevar confusión por considerarse "una simple actitud interior del desprendimiento frente a los bienes de este mundo", y el pobre "sería no tanto el que no posee bienes materiales, sino más bien aquel que -aunque los posea- no está pegado a ellos". ${ }^{31}$

Por consiguiente, no había espiritualización en relación con la 'pobreza del pobre', sino con los que no eran pobres, con los que por mucho que fueran más afortunados desde un punto de vista social y económico, debían asumir una actitud de humildad frente a Dios, poniéndose en contacto con los pobres de veras y comprometiéndose por ellos.

Para Gutiérrez, la acepción de pobreza entendida como 'compromiso de solidaridad y protesta' facilitaba la comprensión del sentido más íntimo y remoto de la misma: la pobreza es un acto de amor y de liberación. Tiene un valor redentor. Si la causa última

27. G. Gutiérrez, Pobres y opción fundamental, en I. Ellacuría, J. Sobrino (eds.), Mysterium liberationis. Conceptos fundamentales de la teología de la liberación, Trotta, Madrid, 1990, pp. 303-321, p. 303.

28. G. Gutiérrez, Teología de la liberación. Perspectivas, cit., p. 365. Si este libro fue su primera obra programática no solo sobre la teología de la liberación, sino también sobre la opción por los pobres, en la última década Gustavo Gutiérrez ha seguido escribiendo acerca de los desheredados: G. Gutiérrez, "Liberation Theology for the Twenty-Fist Century", en P. Hogan Closkey y J. O. Hogan (eds.), Romero's Legacy: The Call to Peace and Justice, Rowman \& Littlefield, New York, 2007; G. Gutiérrez y G. L. Müller, An der Seite der Armen. Theologie der Befreiung, Sankt Ulrich Verlag GmbH, Augsburg.

29. G. Gutiérrez, Teología de la liberación. Perspectivas, cit., p. 366.

30. Ibid., pp. 366-367.

31. Ibid., p. 367. 
de la explotación y alienación del hombre es el egoísmo, la razón profunda de la pobreza voluntaria es el amor al prójimo. La pobreza cristiana no puede, entonces, tener sentido sino como un compromiso de solidaridad con los pobres, con aquellos que sufren miseria e injusticia, a fin de testimoniar del mal que estas -fruto del pecado, ruptura de comunión- representan. No se trata de idealizar la pobreza sino, por el contrario, de asumirla como lo que es: como un mal, para protestar contra ella y esforzarse por abolirla. ${ }^{32}$

De ahí que la tercera acepción fuera la única forma de pobreza aceptable, la que había sido consagrada por la Iglesia del subcontinente como 'opción preferencial por los pobres'; sin embargo, para entender lo que era realmente, era necesario potenciar la 'infancia espiritual'.

Tal como un infante, que no podía expresarse con palabras hasta cuando no aprendiera a hacerlo, de la misma manera el pobre no podía ejercer todas sus capacidades, entregándose espiritualmente en las manos del Todopoderoso hasta cuando no tomara conciencia de su situación y adquiriera cierto discernimiento de sus posibilidades reales.

En otra obra, Gutiérrez también destacaba que el pobre no era un sujeto determinado, sino formaba parte de una colectividad afectada por una conflictividad imperante: de hecho, el pobre aislado no existe. "El pobre pertenece a grupos sociales, razas, clases, culturas, sexo. $\mathrm{Y}$ es precisamente eso lo que hace tan dura y agresiva la irrupción del pobre. Si se tratase de pobres individuales no habría problema; pero como se trata de clases, razas, culturas, condición de la mujer, eso trae tensiones y conflictos [...]. Pobre no es un término tranquilizante [...]. El pobre es el producto -o el subproducto- de un sistema económico y social construido por unos pocos y para su propio beneficio. Hay pues un conflicto estructural que está implicado en la realidad del pobre. Y no sólo eso, la percepción de estas causas lleva a luchar contra ellas; es por ello que decir pobre significa también el pobre en lucha por su liberación, cuestiona radicalmente la sociedad y presenta un desafío a lo que es ser iglesia" ${ }^{33}$ Y el pobre irrumpía en el panorama latinoamericano casi como una presencia totalmente inusual, por estar antes 'ausentes'.

El empleo de este adjetivo tuvo mucha suerte en el vocabulario de Gutiérrez: para él es evidente que los pobres nunca han estado fuera de la historia concreta de América Latina, pero la historia ha sido construida y leída no en función del pobre, sino de los privilegiados que los han humillado y explotado.

32. Ibid., p. 383.

33. G. Gutiérrez, "La irrupción del pobre en América Latina y las comunidades cristianas populares", en S. Torres (ed.), Teología de la liberación y comunidades cristianas de base, Ediciones Sígueme, Salamanca, 1982, pp. 123-142, p. 128. 
Además, el pobre se ha involucrado en la historia latinoamericana de forma chocante: es una entrada dura, que no pide permiso a nadie, a veces violenta. El pobre viene "con su pobreza a cuestas" como decía Bartolomé de Las Casas, con su sufrimiento, con su cultura, con su raza, su lengua, con la explotación que experimenta. Cuando irrumpe lo hace con todo lo que es. ${ }^{34}$

La presencia numerosa de indigentes y necesitados no podía ser desatendida y el teólogo -para Gutiérrez- debía sentirse arrastrado por el deber de evangelizar a esa parte de la población latinoamericana que no quería una fe deformada o distorsionada, sino una inculturación religiosa totalizante, que respetara 'lo cristiano', no obstante el escándalo de la opresión.

Y esto era aún más evidente y necesario puesto que la pobreza también implicaba la muerte, ya sea por hambre, por la enfermedad o por métodos represivos, ${ }^{35}$ una muerte adelantada ${ }^{36}$ por la falta de comida y de hogar, por la imposibilidad de obtemperar a las necesidades de salud y educación, por la explotación en el ambiente laboral, por el desempleo constante, por la falta de respeto de la dignidad humana, por los sufrimientos cotidianos, etc.

En este limitado y, al mismo tiempo, ilimitado universo, el pobre 'hacía teología', pues pensaba la fe y la condición cristiana, ejercía su derecho a pensar, como una manera de afirmar su derecho a la vida que se le negaba rotundamente y de muchas maneras. ${ }^{37}$

Claro estaba, el interés para los pobres no implicaba un exclusivismo, sino una preferencia, una 'opción', una decisión libre y cautivante, una solidaridad profunda y constante.

La moral cristiana obligaba al hombre a alinearse con el pobre, a adentrarse en su falta de vida, mejor dicho, en su supervivencia.

También la Conferencia de Medellín había demostrado entender estas consideraciones y sus documentos finales más veces apelaron a la organización de los pobres en vistas a la construcción de una sociedad justa. ${ }^{38}$

\footnotetext{
34. Ibid., p. 124.

35. G. Gutiérrez, La verdad os hará libres, Ediciones Sígueme, Salamanca, 1990, cap. I.

36. G. Gutiérrez, La fuerza histórica de los pobres, Ediciones CEP, Lima, 1979. Además, "el opresor reprime todo indicio de que hay pobreza en América latina. Esa es la razón de la prisión, el exilio, la tortura, la muerte de tantos hermanos; con muchos de ellos hemos compartido experiencias, reflexiones en encuentros [...]. Esos hermanos y hermanas, esos mártires, atestiguan que los pobres 'mueren antes del tiempo' por el hombre y por las balas. Es por ello que sus cadáveres resultan subversivos, y que tantas veces, a lo largo del continente, el poder represivo no los entrega y miente sobre las condiciones en que ocurrieron esas muertes. No percibe el dominador que pasar por la experiencia y la crisis del 'sepulcro vacío' fue para los amigos de Jesús, y es para sus seguidores de hoy, lo que les permitió comprender la plenitud de vida del resucitado que vence toda muerte". Cfr. G. Gutiérrez, "La irrupción del pobre en América Latina y las comunidades cristianas populares", cit., pp. 128-129.

37. G. Gutiérrez, "Impegno teologico ed esperienza ecclesiale", en Concilium, Popolo di Dio tra i poveri, a. XX, fasc. 6, 1984, pp. 109-115, p. 112.

38. Cfr. G. Gutiérrez, La densidad del presente, Ediciones Sígueme, Salamanca, 2003.
} 
Tal como Gustavo Gutiérrez, prácticamente todos los teólogos de la liberación hicieron hincapié en esta faceta escasamente considerada hasta aquel entonces, que empezó a ser el impulso fundamental, el punto de partida y de llegada de su reflexión teológica.

La comunidad cristiana, la base en la que ellos actuaron, fue una de las realidades más fecundas de la Iglesia latinoamericana, destacada por el Concilio Vaticano II y por aquel mismo pueblo que llevaba esperando la transformación total de la historia para que los últimos pudieran convertirse realmente en los primeros.

\section{Conclusiones}

Después de casi medio siglo de su nacimiento, la teología de la liberación sigue cosechando interés, y prueba de ello son los centenares de libros que siguen editándose en todo el mundo sobre este 'discurso acerca de Dios', lo cual implica que la carga emocional que había acompañado su presentación aún no se ha apaciguado.

Está claro que en la iglesia popular del subcontinente la teología de la liberación ha perdido aquellas dimensiones que, en los años pasados, la convirtieron en dominante e indispensable y que para difenderla muchos hombres, religiosos y laicos incluso murieron en los trances de cambiar un status quo de siglos de historia que se había enraizado hasta parecer imposible subvertirlo.

Sin embargo, los orígenes argentinos del pontífice Francisco no traicionan su interés y ahínco constantes para los necesitados y desheredados del mundo, por lo cual se vuelve a hablar de 'Iglesia de los pobres'. ${ }^{39}$

Además, persisten la obra y el testimonio de aquellos mismos teólogos de los años sesenta y setenta del siglo pasado que, en los últimos tiempos, han desplazado su atención también sobre otras cuestiones, la ecología, la condición de la mujer, la perspectiva de la liberación también en otros países y continentes.

De ahí que la querelle postconciliar siga repercutiéndose en el mundo actual, sobre todo en un continente que, a pesar de haber luchado a lo largo de los siglos para liberarse de la invasión y del poder de dominadores y colonizadores para lograr la independencia y, tras haberla conquistado, para huir del sometimiento a regímenes militares despóti-

39. A este propósito, cfr. N. Capovilla y B. Tusset, Esclusi. Nelle periferie esistenziali con Papa Francesco, Paoline Editoriale Libri, Milano, 2014; L. Bettazzi, La Chiesa dei poveri dal Concilio a Papa Francesco, Pazzini Editore, Villa Verucchio (RN), 2014; F. Cupello, Chiesa povera, non impoverita. Papa Francesco e i rischi del pauperismo, Fede \& Cultura, Verona, 2014 ; G. Cionchi, Papa Francesco 'il rivoluzionario', Albatros, Roma, 2015; etc. 
cos y anticonstitucionales, busca conquistar la autonomía y la correcta colocación para todos sus componentes sociales, sobre todo para los emarginados.

Podríamos incluso decir -sin temor a equivocarnos- que esto sigue siendo -antaño como ahora- el gran criterio hermenéutico de la teología de la liberación, que ella existió por el pobre y que en la realidad de éste halló su origen y destino, en una palabra, su liberación. 